\title{
SCANNING ELECTRONMICROSCOPIC STUDIES OF BORDETELLA BRONCHISEPTICA ON THE RABBIT TRACHEAL MUCOSA
}

\author{
T. Matsuyama and T. Takino \\ Department of Bacteriology, Osaka City University Medical School, \\ Abeno-ku, Osaka 545, Japan
}

\section{Plates VIII-XI}

IN previous studies Bordetella pertussis was shown to be resistant to the mucociliary clearance mechanism of the rabbit trachea (Matsuyama, 1977). Scanning electron microscopy readily demonstrated $B$. pertussis organisms associated with clusters of the cilia of the epithelial cells. A similar association has been described in chick organ cultures (Iida and Ajiki, 1974, 1975) and hamster organ cultures (Collier, Peterson and Baseman, 1977; Muse, Collier and Baseman, 1977). B. pertussis is not a natural pathogen of the rabbit, chick or hamster; on the other hand, Bordetella bronchiseptica is a natural respiratory-tract pathogen of the rabbit and the dog (Wilson and Miles, 1975). Bemis, Greisen and Appel (1977) demonstrated experimentally the strong affinity of $B$. bronchiseptica for the canine respiratory tract; they also mentioned similarities between the respiratory infections produced by $B$. pertussis and $B$. bronchiseptica.

In the present study, scanning electron microscopy has been used to observe infections of the rabbit tracheal mucosa with B. bronchiseptica, and with Staphylococcus aureus-an organism that has no special predilection for the respiratory tract.

\section{MATERIALS AND METHODS}

Bacterial strains. B. bronchiseptica strain 5376 was supplied by Dr Y. Sato, National Institute of Health, Tokyo, Japan, and was grown either on Bordet-Gengou agar medium containing $20 \%$ defibrinated rabbit blood or in a liquid medium containing anion-exchange resin (Kuwajima, Matsui and Kishigami, 1957); it was a phase-1 organism (Nakase, 1957). S. aureus strain 209P was obtained from the culture collection of this department, and grown either on Heart Infusion Agar (Nissui, Tokyo) or in Penassay Broth (Difco, Detroit, Michigan, USA).

Tracheal cultures. Embedded rabbit tracheal cultures (ERTC) were prepared as described previously (Matsuyama, 1974). The L-15 Medium used (Grand Island Biological Co., Grand Island, New York, USA) was kept in a humidified environment in a sealed box. Tracheal preparations shown by sterility tests in Thioglycollate Medium (Nissui, Tokyo) to be contaminated with bacteria were discarded. Tracheal preparations were also made from rabbits that possessed serum containing $B$. bronchiseptica agglutinins; serum agglutinin levels were determined with the microtitre equipment described by Manclark (1976).

Point inoculation. Bacterial suspensions were "point inoculated" on to one-day ERTC with a platinum microloop as described by Maysuyama (1974). The infecting bacteria were traced by touching the mucous surface with a platinum coil and "stamping" an agar plate with the coil as described by Matsuyama (1974).

Scanning electron microscopy. Each explant was washed with $2 \mathrm{ml}$ of saline, expelled through a 22-gauge needle at the rate of $0.6-0.8 \mathrm{ml} / \mathrm{s}$ to free the ciliated surfaces from mucus. Fixation and observation were as described previously (Matsuyama, 1977). 


\section{RESULTS}

\section{B. bronchiseptica infection}

Two days after inoculation with $B$. bronchiseptica strain 5376 the infected mucous membrane of the ERTC was observed with a scanning electron microscope. Unlike the uninoculated mucous membrane (fig. 1), the infected mucous membrane was partly denuded of cilia (fig. 2). Tufts of remaining cilia were entangled with large numbers of bacteria (fig. 2). Extrusions of epithelial cells carrying many bacteria among the cilia were frequently observed (fig. 3), but it was difficult to find bacteria in non-ciliated areas.

Sera from some rabbits contained $B$. bronchiseptica agglutinins at titres that did not exceed 128; these agglutinins presumably resulted from natural infection. Explants from rabbits with such agglutinins were infected with $B$. bronchiseptica and observed with a scanning electron microscope. The cilia were entangled with large numbers of bacteria; no differences were recognised between explants from rabbits with agglutinins and those without.

A second phase-l strain (M1) of B. bronchiseptica was examined. This strain, from a guinea-pig, was supplied by Dr Y. Nakase, Kitasato Institute, Tokyo; its behaviour on rabbit tracheal mucosa was similar to that of strain 5376.

\section{S. aureus infection}

Two days after inoculation with $S$. aureus, the area of the mucous membrane showing bacterial growth by the "stamping method" was observed with a scanning electron microscope. Partial disappearance of cilia and extrusion of epithelial cells were easily recognised. However, it was extremely difficult to find the infecting bacteria on these damaged areas. Most of the remaining cilia were free from bacteria (fig. 4). S. aureus seemed to have no intimate contact with tufts of cilia of the extruding epithelial cells (fig. 5).

\section{DisCussion}

Infection of ERTC with B. bronchiseptica, like infection with B. pertussis (Matsuyama, 1977), resulted in intimate interactions between bacteria and ciliated epithelial cells. On the mucous membrane infected with $B$. bronchiseptica most of the remaining cilia were entangled with large numbers of bacteria. This was in clear contrast to the mucous membrane infected with $S$. aureus. It was extremely difficult to find $S$. aureus on the mucous membrane; even when infecting bacteria were seen, there were no intimate interactions between them and the mucous membrane. Most of the $S$. aureus cells were probably lost in the washing process that preceded the scanning electron microscopy; light microscopy showed that unwashed explants carried many S. aureus cells (Matsuyama, 1974).

Although the precise mechanism for the interaction between $B$. bronchiseptica and the beating cilia has not yet been elucidated, the phenomenon may be important in relation to pathogenesis. B. bronchiseptica infection usually started from the point-inoculated site on the ERTC, as in B. pertussis infection (Matsuyama, 1977). It seems possible that the interaction between cilia and organisms assists $B$. bronchiseptica in persisting in the respiratory tract. Recently, delayed clearance of $B$. bronchiseptica from the infected canine trachea was shown by a study of aerosol infection. B. bronchiseptica required 14 weeks to be cleared from the trachea of an infected dog; in contrast, S. aureus and other organisms were cleared in 1-3 days (Bemis et al., 1977).

Organ cultures in liquid medium have been used to study specific interactions between micro-organisms and epithelial cells; such studies have been confined to infections with viruses, mycoplasmas, and a few species of bacteria lacking the ability to grow in the medium itself. ERTC and the point-inoculation method have made possible the study of infections of the mucous membrane with several species of bacteria. 


\section{B. BRONCHISEPTICA ON THE TRACHEAL MUCOSA}

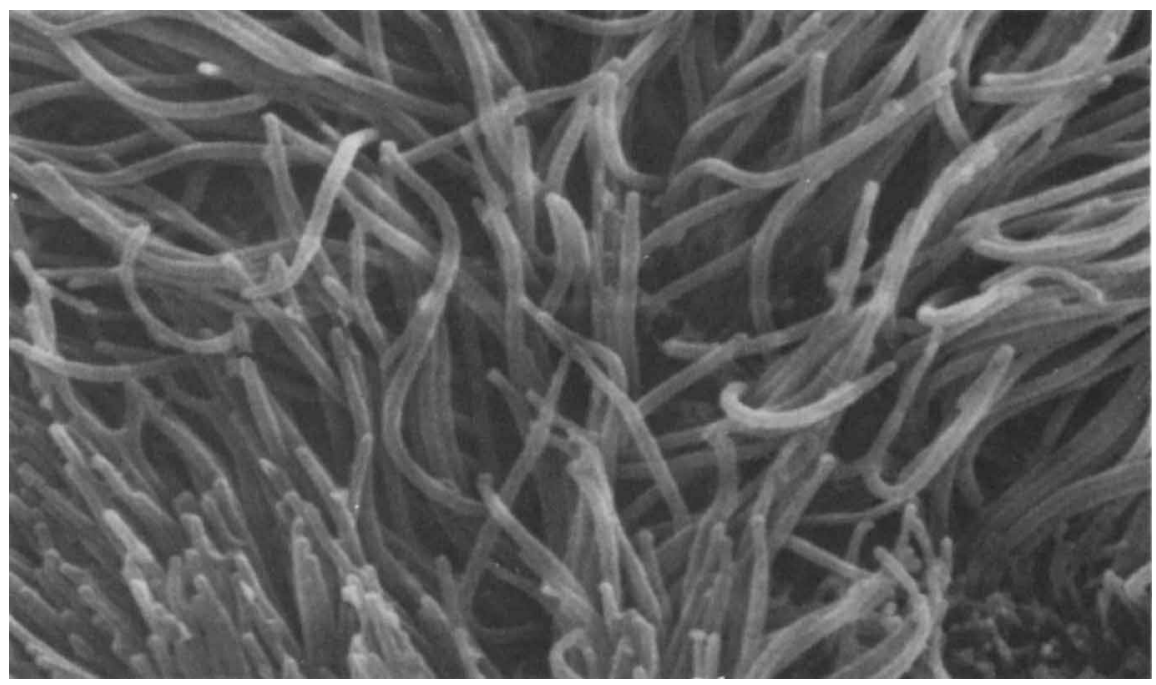

Fig. 1.-Mucous membrane of an uninfected rabbit tracheal explant. Scanning electron micrograph $(\mathrm{SEM}) . \times 9300$.

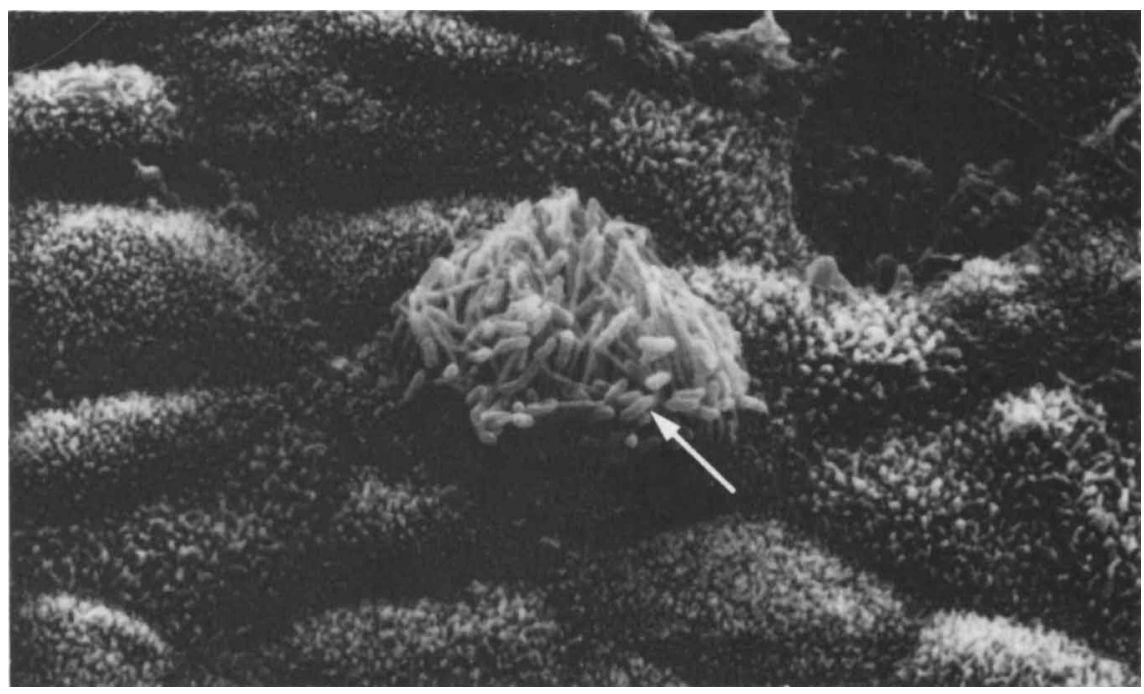

FiG. 2.-Mucous membrane of a rabbit tracheal explant, 2 days after inoculation with Bordetella bronchiseptica. Cilia are entangled with infecting bacteria (arrow). SEM. $\times 3300$ 


\section{B. BRONCHISEPTICA ON THE TRACHEAL MUCOSA}

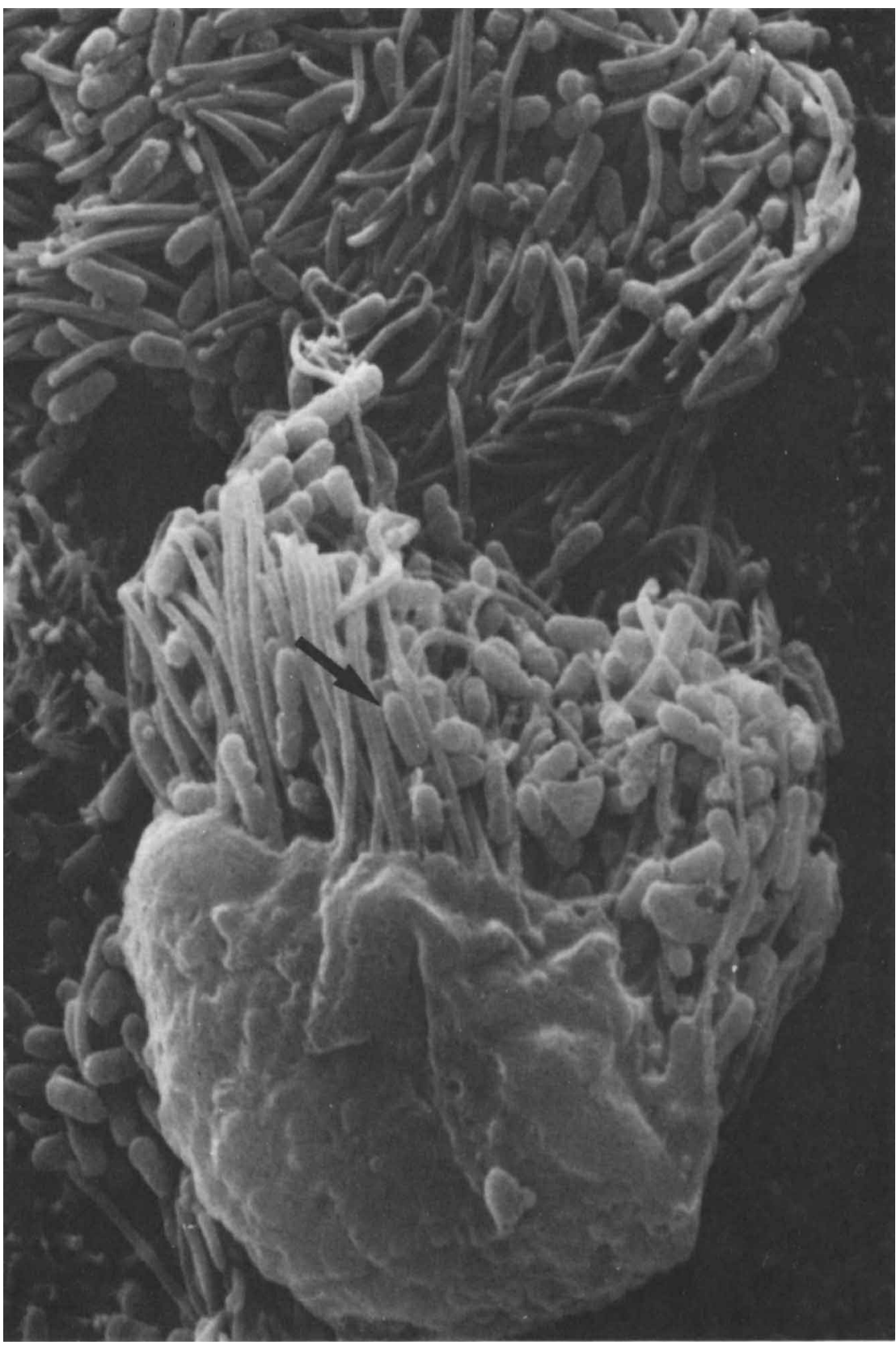

FIG. 3.--An extruding ciliated epithelial cell and infecting bacteria (arrow), 2 days after inoculation with $B$. bronchiseptica. SEM. $\times 9900$. 


\section{B. BRONCHISEPTICA ON THE TRACHEAL. MUCOSA}

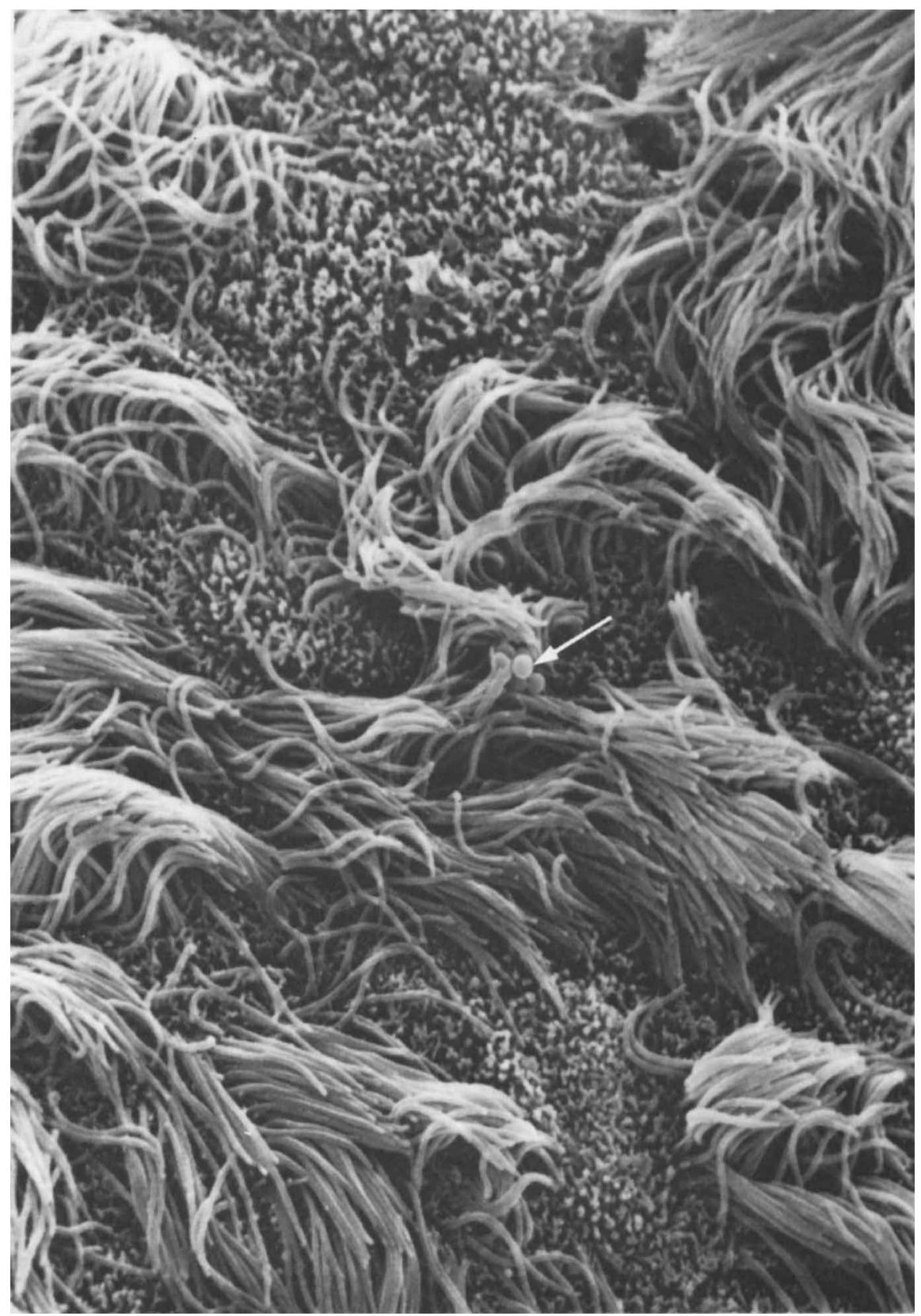

Fig. 4.-Mucous membrane of rabbit tracheal explant, 2 days after inoculation with Staphylococcus aureus. Most of the cilia are free from bacteria (arrow). SEM. $\times 4600$. 


\section{B. BRONCHISEPTICA ON THE TRACHEAL MUCOSA}

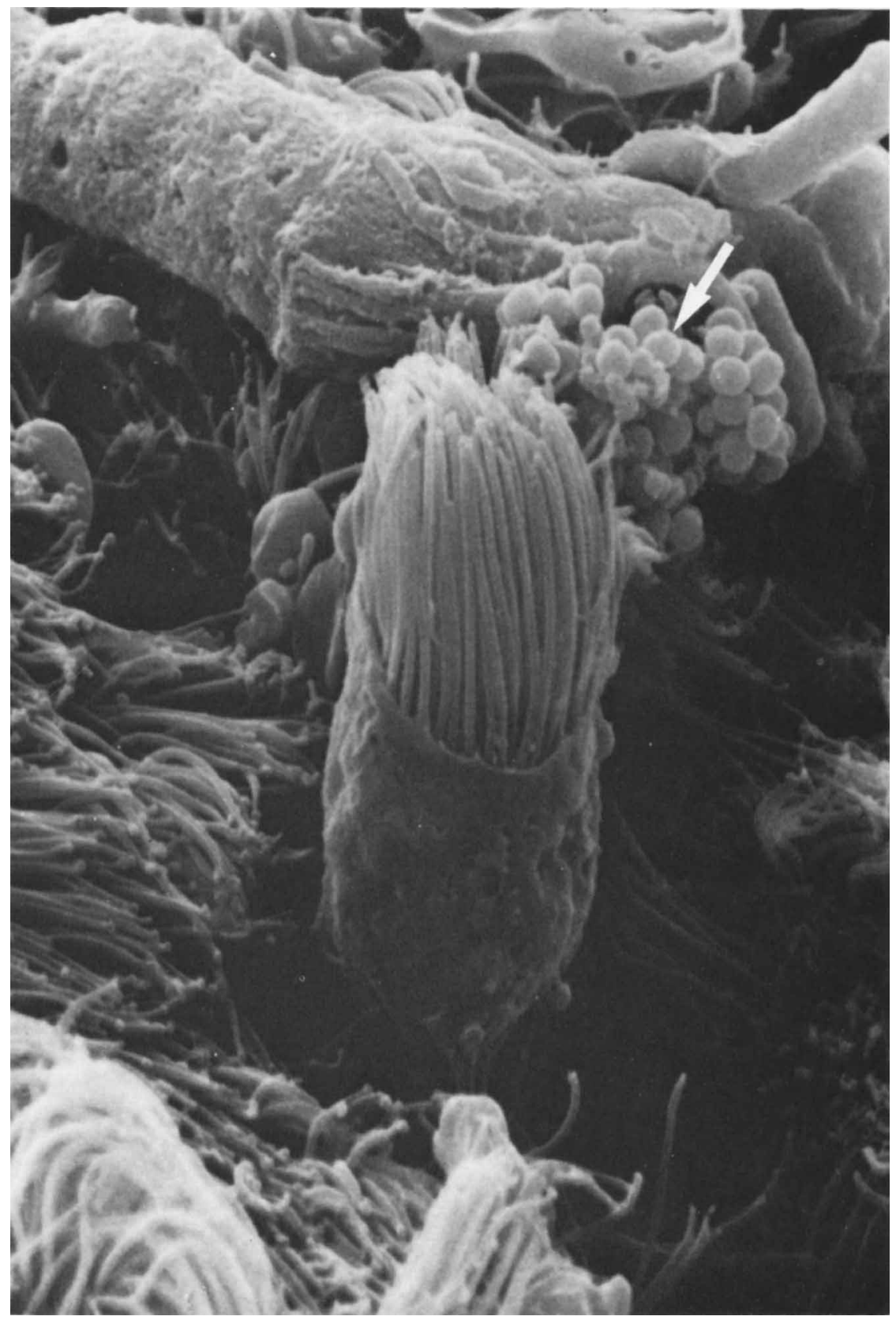

FIG. 5.-An extruding ciliated epithelial cell and infecting bacteria (arrow), 2 days after inoculation with $S$. aureus. SEM. $\times 8300$. 


\section{SUMMARY}

Rabbit tracheal mucous membrane cultivated on solid agar medium was infected with either Bordetella bronchiseptica or Staphylococcus aureus. Scanning electron microscopy revealed that large numbers of $B$. bronchiseptica cells became entangled with the cilia of the tracheal epithelial cells. In contrast, $S$. aureus cells showed no such intimate interaction with the cilia.

We thank Dr Y. Sato, National Institute of Health, Tokyo, and Dr Y. Nakase, Kitasato Institute, Tokyo, for supplying the strains of B. bronchiseptica and Dr C. Sweet and Professor H. Smith, Department of Microbiology, University of Birmingham, for their critical reading of this manuscript. This work was supported in part by a grant from the Scientific Research Fund of the Ministry of Education, Japan.

\section{REFERENCES}

Bemis, D. A., Greisen, H. A. AND Appel, M. J. G. 1977. Pathogenesis of canine bordetellosis. J. infect. Dis., 135, 753.

Collier, A. M., Peterson, L. P. And Baseman, J. B. 1977. Pathogenesis of infection with Bordetella pertussis in hamster tracheal organ culture. J. infect. Dis., 136, suppl., S196.

IDDA, T. AND AJIKI, Y. 1974. Growth characteristics of Bordetella pertussis in the chick tracheal organ culture. Jap. J. Microbiol., 18, 119.

IIDA, T. AND AJIKI, Y. 1975. The effect of 2,4-dinitrophenol on the growth of Bordetella pertussis in the chick tracheal organ culture. Jap. J. Microbiol., 19, 381.

Kuwajima, Y., Matsui, T. And Kishigami, M. 1957. The growth-supporting effect of some anion exchange resins for phase I Haemophilus pertussis. Jap. J. Microbiol., 1, 375.

MANCLARK, C. R. 1976. Serological response to Bordetella pertussis. In Manual of clinical immunology, edited by N. R. Rose and H. Friedman. American Society for Microbiology: Washington, DC, p. 312.

Matsuyama, T. 1974. Point inoculation of cultivated tracheal mucous membrane with bacteria. J. infect. Dis., 130, 508.

Matsuyama, T. 1977. Resistance of Bordetella pertussis phase I to mucociliary clearance by rabbit tracheal mucous membrane. J. infect. Dis., 136, 609.

Muse, K. E., Collier, A. M. and Baseman, J. B. 1977. Scanning electron microscopic study of hamster tracheal organ cultures infected with Bordetella pertussis. J. infect. Dis., 136, 768.

NAKASE, Y. (1957). Kitasato Archs exp. Med., 30, 1. Studies on Haemophilus bronchisepticus.

Wilson, G. S. AND Miles, A. 1975. Topley and Wilson's Principles of bacteriology, virology and immunity, 6th ed. Arnold: London, vol. 1, p. 1036. 